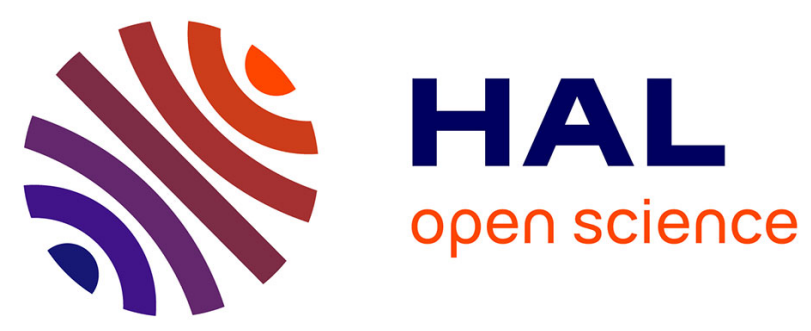

\title{
Operating Curves Based Working Capital Management for Engineer to Order Manufacturers
}

Dennis Schiemann, Sudharshan Santhanam, Günther Schuh

\section{To cite this version:}

Dennis Schiemann, Sudharshan Santhanam, Günther Schuh. Operating Curves Based Working Capital Management for Engineer to Order Manufacturers. IFIP International Conference on Advances in Production Management Systems (APMS), Sep 2017, Hamburg, Germany. pp.259-267, 10.1007/9783-319-66926-7_30. hal-01707289

\section{HAL Id: hal-01707289 \\ https://hal.inria.fr/hal-01707289}

Submitted on 12 Feb 2018

HAL is a multi-disciplinary open access archive for the deposit and dissemination of scientific research documents, whether they are published or not. The documents may come from teaching and research institutions in France or abroad, or from public or private research centers.
L'archive ouverte pluridisciplinaire HAL, est destinée au dépôt et à la diffusion de documents scientifiques de niveau recherche, publiés ou non, émanant des établissements d'enseignement et de recherche français ou étrangers, des laboratoires publics ou privés. 


\title{
Operating Curves based Working Capital Management for Engineer to Order Manufacturers
}

\author{
Dennis Schiemann, Sudharshan Santhanam, Günther Schuh \\ ${ }^{1}$ FIR at the RWTH Aachen University, 52074 Aachen, Germany \\ ${ }^{2}$ Springer Heidelberg, Tiergartenstr. 17, 69121 Heidelberg, Germany \\ Incsespringer.com
}

\begin{abstract}
Working capital management is one of the key disciplines that must be prudently monitored for a firm in pursuit of profits, liquidity and growth. The focus of this paper is on the engineer-to-order manufacturers, and the objective is to analyze the correlations between the reference processes of the engineer-toorder production approach with the key postulates of working-capital management and deliver a mathematical operating curves model, whose purpose and goal is basing on the rationale, that is underlying in the parent logistic operating curves theory.
\end{abstract}

Keywords: Working capital management, engineering to order, logistics operation curves

\section{Introduction}

The appropriate levels of current assets and current liabilities, the way in which the short-term requirements of the firm are financed and the composition of the short-term and long-term financing, all involves a trade-off between the profitability and risk. The conceptual evaluation of the working-capital management, the engineering to order production approach and the operating curves theory accounts this trade-off to strike a sensible balance between the profit and the risk involved.

\section{Analysis of Key Concepts}

\subsection{Working Capital Management}

Working capital management refers to the underlying, structured and effect-oriented analysis to make comprehensive and sensible, short-term financial decisions. Shortterm financial decisions seem relatively less complex to make, than the process for long-term and medium-term ones but are equally important and critical. This fact is put explicitly, as an organization still could fail in spite of identifying valuable investment opportunities, most optimal capital structure and most perfect dividend policies, just because it emphasized lesser on short-term planning. [1]. The net-working capital of a 
firm is defined as its current assets minus its current liabilities. The net-working capital is that capital required by the firm to satisfy its short-term capital requirements. [1] [2]. The working capital accounts implicate the free-cash-flow of the firm. The direct reason and relevance comes from the cash-cycle. The cash-conversion-cycle is an important concept in the working-capital management that potentially affects the components of working-capital. The cash-conversion-cycle is mathematically summarized as CashConversion-Cycle $=($ Inventory Period + Receivables Period $)-$ Accounts Payable Pe$\operatorname{riod}[1]$.

\subsection{Engineer to Order Production Approach}

The continuously increasing demand for specific customer value orientation and the need to develop customized parts with longer lead times, expensive capital investments and technical expertise, is promoting the role of engineer-to-order manufacturers in the supply chain. The engineer-to-order (ETO) production approach enables firms to have increased agility and flexibility, positioning them ideally to respond against unexpected and rapid market shifts through their production of one-of-a-kind products. [3]. But given all this, there has been relatively lesser research outputs exclusively to the ETO production models. [4, 5]. Given a high level of product complexity and customization, engineer-to-order companies account critical factors during their planning phase as significant uncertainty in the operating times, limited resources to respond in a situation of demand fluctuation and complexity and concurrent product developments. [6].

\subsection{Logistic Operation Curves Theory}

With difficulties in quantifying large number of variables and the limitations associated with the mathematical functions that could approximate the required primary scenario as close as possible, a complex production system cannot be absolutely reflected in a mathematical model. The activities within the production processes hence must be classified with respect to their objectives in the value chain. Production and testing, transportation, and storage and supply are defined as the primary reference processes. [7]. Due to the embodied conflict in the objectives of the primary production reference process, it has been difficult for the practitioners to quantify the variables and interdependencies and thereby perform a targeted logistics positioning. Intuitive and experience driven decisions addressing this trade-off results in an imbalance, given the complexity of the production process. The logistics operating curves theory addresses this difficulty in quantifying the trade-off and interdependency between the objectives of the production reference process. A logistic operating curve visually represents the correlation between a specific parameter of interest (the objective or dependent variable) and an independent variable. Therefore, for every value of the independent variable that can be changed by external conditions, at least one value can be determined for the objective. [7]. 


\section{Operating Curves based Working Capital Management for Engineer to Order Manufacturers}

The targeted mathematical operating curves model must adhere to the ground rule stipulated by its parent logistic operating curves model, which is targeted logistic positioning between the key, fundamental and trade-off variables in production logistics viz: work-in-process (WIP) and the maximum possible output rate. Attempting the best to adhere to this ground rule, the ideal solution is to create a targeted positioning between the key trade-off variables that encompasses into its scope, the concept of workingcapital management, ETO production approach and the operations of the ETO manufacturers. The key trade-off concept of corporate finance viz: profitability and the risk would address the challenge of encompassing the scope and are potential fundamental variables in the proposed operating curves model. The effectiveness of these potential fundamental variables in encompassing the scope could only be realized when the concepts of capital budgeting are included in the analysis. Hence the need for taking the concepts of capital budgeting becomes important and relevant.

\subsection{Definition of Ideal and Calculated Operating Curves.}

As already stated the Operating Curves Model must at any chance not deviate the Basic and Fundamental, Yet Key and Very Important Answer that has been Delivered by the Parent Logistic Operating Curves Model- Which is the basis for this Operating Curves Model, to the Question of Conducting a Targeted Logistic Positioning.

This hence has become a Ground Rule stipulated by the Parent Logistic Operating Curves Model, to the Operating Curves Model. To answer this Ground Rule, this model should conduct a Targeted Positioning between Two Key Trade-Off Variables.

While there are Many Pairs or at least more than one pair of Trade-Off Variables, on a Holistic Approach and to answer the Problem Statement in Full and Complete, the Trade-off Variable that is of Potential Interest must encompass, in its scope the Underlying Concept of Working-Capital Management, the ETO Production Approach and the Operations of ETO Manufacturers.

While pursuing a Bottom-Up Approach from a Pure Operational Perspective to a Pure Financial Perspective although initially was felt much logical, could not contribute sufficiently and effectively towards Zero-in-On of a pair that can satisfy the Challenging Conditions and the Scenario that is being attempted to fulfill. Hence pursuing a Top-Down Approach from a Pure Financial Perspective to a Pure Operational Perspective, the Key Trade-Off Concept of Micro-Economics, thereby of Corporate Finance of which the Concept of Working-Capital Management is a part. Profitability and Risk would address the challenge of encompassing the scope. This is a solution to the scenario for which the Operating Curves Model is being attempted to be built, and are hence declared as the Potential Fundamental Variables for the Operating Curves Model. The Declaration of Potential Variables of Interests Representing Conceptual WorkingCapital Management are described and the Four Distinct Operating States that Encompass the Given Scenario will be shown in Fig. 1. Operation State (OS) 1 is Organic and 
Non-Significant Risk Growth as well as Organic and In-Organic Profit Growth. OS 2 is Organic, Partially In-Organic and Non-Significant-to-Significant Average Risk Growth as well as Organic and Reduced (Relative to State 1) In-Organic Profit Growth. OS 3 is In-Organic and Organic Steady and Sustained Risk Growth as well as Implicated Organic Profit Growth. OS 4 Increased Organic and Significant In-Organic Risk Growth as well as Plummeting Organic Profit Growth.

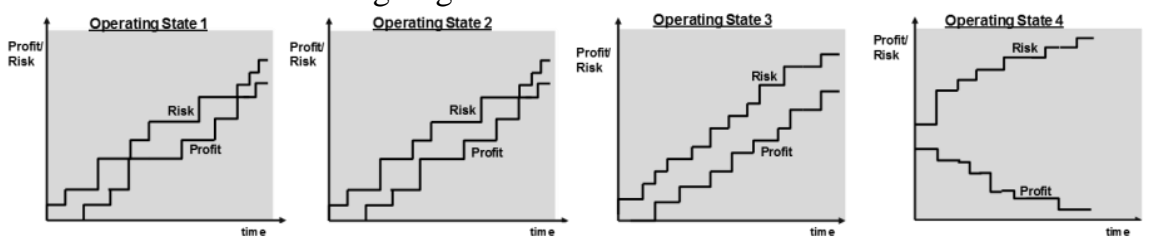

Fig. 1. Four Distinct Operating States that Encompass the Given Scenario

Additional Cost Incurred by the Firm to Provide Necessary Liquidity Cushion, when its estimates face Upside Deviation. $(\boldsymbol{A C})$

$A C=T C_{\text {Changed }}-T C[\$]$.

$\mathrm{TC}=\left[\mathrm{R}_{\mathrm{c}}[\$] \times \mathrm{O}_{\mathrm{c}}[\%]\right]+[\mathrm{n} \times \mathrm{AT}[\$]][\$]$

$\mathrm{TC}_{\text {Changed }}=\left[\left[\mathrm{R}_{\mathrm{c}-\text { Actual }}[\$] \times \mathrm{O}_{\mathrm{c}}[\%]\right]+[\mathrm{n} \times \mathrm{AT}[\$]][\$]\right.$

The Opportunity Costs Foregone by the Firm from Investing in Other Attractive Opportunities, due to its decision to pay a Reduced Monthly Principal Dues. $\left(\boldsymbol{O} \boldsymbol{C}_{\boldsymbol{E} \text { MSD }}\right)$

$O C_{E M S D}=P[\$] \times[H F I R[\%]-F I R[\%]][\$]$

The Opportunity Cost that is Foregone by the Firm from Investing in Attractive Opportunities due to a Postponement in the Repayment Schedule of its Debt. $\left(\boldsymbol{O C} \boldsymbol{C}_{\boldsymbol{P R} \boldsymbol{R} \boldsymbol{D} \boldsymbol{D}}\right)$

$\left(O C_{P R P S D}\right)=\left[[X[\$]+X[\$] . F I R[\%]] . F I R^{2}[\%]+[Y[\$]+\right.$
$Y[\$] . F I R[\%]] . F I R[\%]+[Z[\$]+Z[\$] . F I R[\%]]]-[[X[\$]+$
$X[\$] . F I R[\%]]+[Y[\$]+Y[\$] . F I R[\%]]+[Z[\$]+Z[\$] . F I R[\%]]]$.

The Magnitude by which the Profitability on Additional Sales-Generated due to a Relaxed Credit Standard, exceeding the Required Rate of Return on Additional Underlying Investment $\left(\boldsymbol{M}-\boldsymbol{R} \boldsymbol{C}_{\boldsymbol{P}_{A S}>\boldsymbol{U}_{I n v}}\right)$

$\left(M-R C_{P_{A S}>U_{\text {Inv }}}\right)=\left[\right.$ Profit $_{T_{S V_{\text {Increased }}}-T S V}-\left[\left[\right.\right.$ AI $\left.\left.\left._{\text {TSV }_{\text {Increased }}-A_{T S V}}\right] \times R[\%]\right]\right](6)$

The Proportion of Receivables that is Defaulting $\left(\boldsymbol{D} \boldsymbol{F}_{\boldsymbol{R C T}}\right)$

The Magnitude by which the Profitability of Additional Sales, after Bad-Debt Losses - Generated Due to Re-Calibrated Credit-Terms, exceeding the Required Return on Un-

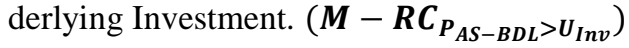


$\left(M-R C_{P_{A S-B D L}>U_{I n v}}\right)=\left[\left[\right.\right.$ Profit $\left._{T S V_{\text {Increased }}-T S V}\right]-\left[C_{D F_{R C T}}\right]-$
$\left[\left[\right.\right.$ AI $\left.\left.\left._{\text {TSV }_{\text {Increased }}-A_{\text {ISV }}}\right] \times R[\%]\right]\right]$

The Magnitude by which the Reduction in the Cost of Bad-Debt Losses exceeding Additional Collection Expenditures $\left(\boldsymbol{M}_{\boldsymbol{R} C \boldsymbol{B} \boldsymbol{B}>\boldsymbol{A C E}}\right)$

$\left(M_{R C B>A C E}\right)=\left[\left[C_{D F_{R C T}}[\$]-L C_{D F_{C P}}[\$]\right]\right]-\left[C_{C P 2}[\$]-C_{C P 1}[\$]\right]$

Configuring these Potential Fundamental Variables to be an even effective TradeOff Variables and analogous to those in the Parent Logistic Operating Curves Model, these become Maximum Possible Profit Profit Max $_{\text {and }}$ ane Ideal Minimum Risk Ideal Risk $k_{\text {Min }}$ (see Fig. 2).

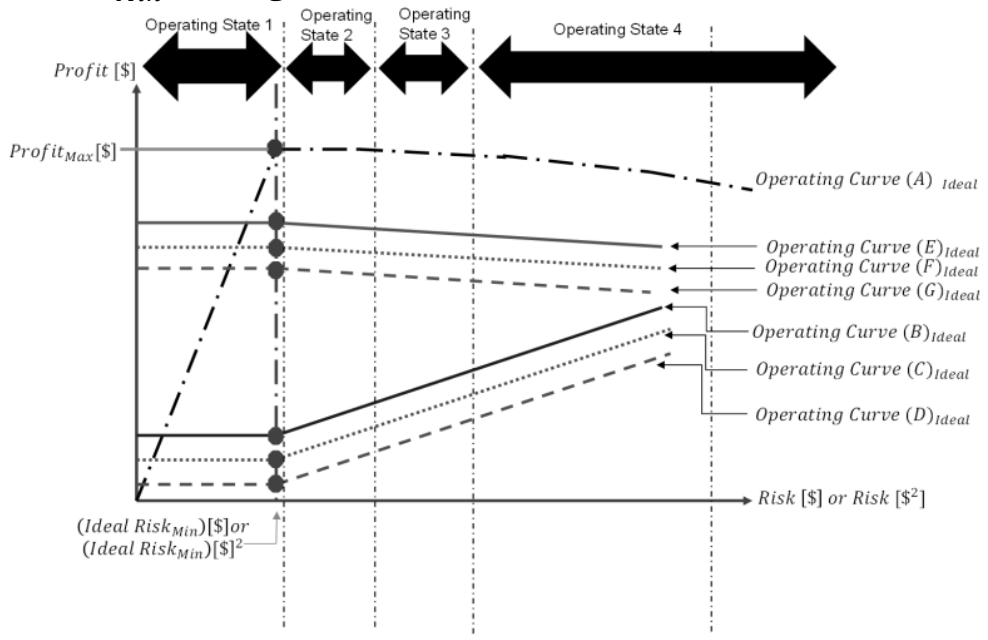

Fig. 2. Ideal Operating Curves Model

Operating Curve $(A)_{\text {Ideal }}$ :

Profit $_{\text {Max }}[\$]$ vs. $\left(\right.$ Ideal Risk $\left._{\text {Min }}\right)[\$]$ or $\left(\right.$ Ideal Risk $\left._{\text {Min }}\right)[\$]^{2}$

Operating Curve $(B)_{\text {Ideal }}$ :

$(A C)[\$]$ vs. $\left(\right.$ Ideal Risk $\left._{\text {Min }}\right)[\$] \operatorname{or}\left(\right.$ Ideal Risk $\left._{\text {Min }}\right)[\$]^{2}$

Operating Curve $(C)_{\text {Ideal }}$ :

$\left(O C_{E M S D}\right)[\$]$ vs. $\left(\right.$ Ideal Risk $\left._{\text {Min }}\right)[\$]$ or $\left(\right.$ Ideal Risk $\left._{\text {Min }}\right)[\$]^{2}$

Operating Curve $(D)_{\text {Ideal }}$

$\left(O C_{P R P S D}\right)[\$]$ vs. $\left(\right.$ Ideal Risk $\left._{\text {Min }}\right)[\$] \operatorname{or}\left(\right.$ Ideal Risk $\left._{\text {Min }}\right)[\$]^{2}$

Operating Curve $(E)_{\text {Ideal }}$ :

$\left(M-R C_{P_{A S}>U_{I n v}}\right)[\$]$ vs. $\left(\right.$ Ideal Risk $\left._{\text {Min }}\right)[\$]$ or $\left(\right.$ Ideal Risk $\left._{\text {Min }}\right)[\$]^{2}$ 
Operating Curve $(F)_{\text {Ideal }}$ :

$\left(M-R C_{P_{A S-B D L}>U_{I n v}}\right)[\$]$ vs. $\left(\right.$ Ideal Risk $\left._{\text {Min }}\right)[\$] \operatorname{or}\left(\right.$ Ideal Risk $\left._{\text {Min }}\right)[\$]^{2}$

Operating Curve $(G)_{\text {Ideal }}$ :

$\left(M_{R C B>A C E}\right)[\$]$ vs. $\left(\right.$ Ideal Risk $\left._{M i n}\right)[\$] \operatorname{or}\left(\right.$ Ideal Risk $\left._{M i n}\right)[\$]^{2}$

\subsection{Underlying Procedures Involved in defining the Calculated Operating Curves.}

The following equations 16 to 23 are a straight forward answer to the research questions. The Left Hand Side of the equations represent the variables that are identified from the analysis; and that which represent the efficiency of working-capital management of the firm. The Right Hand Side of the equations represent mathematical relationship that accounts the effects of operational variables, identified as potential for the engineer-to-order manufacturers. Equations 18 and 19 are a robust correlation between the extremities and the mean value of the fundamental trade-off variables.

$\left(\right.$ Risk $\left._{\text {Mean }}\right)[\$]$ or $[\$]^{2}\{t\}=\left(\right.$ Ideal Risk $\left.k_{\text {Min }}\right)[\$]$ or $[\$]^{2} \cdot\left(1-\sqrt[C]{1-t^{C}}\right)+$ $\alpha_{1}$. Ideal Risk $\left._{\text {Min }}\right)[\$]$ or $[\$]^{2} . t$

Profit $_{\text {Mean }}[\$]\{t\}=$ Profit $_{\text {Max }}[\$] \cdot\left(1-\sqrt[c]{1-t^{C}}\right)$

$(\mathrm{AC})[\$]\{\mathrm{t}\}=\psi \times\left(\right.$ Ideal Risk $\left.\mathrm{Min}_{\mathrm{M}}\right)[\$]$ or $[\$]^{2} \cdot\left(1-\sqrt[\mathrm{C}]{1-\mathrm{t}^{\mathrm{C}}}\right)+$ $\alpha_{1}$. (Ideal Risk $\left.\mathrm{Min}_{\text {Min }}\right)[\$]$ or $[\$]^{2}$.t-

$\left(O C_{E M S D}\right)[\$]\{t\}=\psi_{O C_{E M S D}} \times\left(\right.$ Ideal Risk $\left._{\text {Min }}\right)[\$]$ or $[\$]^{2} \cdot\left(1-\sqrt[\mathrm{C}]{1-\mathrm{t}^{\mathrm{C}}}\right)+$ $\alpha_{1}$. (Ideal Risk Min $)[\$]$ or $[\$]^{2} . \mathrm{t}, \quad$ Where $\quad \psi_{O C_{E M S D}}=$ Constant, $\psi_{O C_{E M S D}}>$ 0 and Due to (HFIR [\%] - FIR [\%]) (19)

$\left(O C_{P R P S D}\right)[\$]\{t\}=\psi_{O C_{P R P S D}} \times\left(\right.$ Ideal Risk $\left._{\text {Min }}\right)[\$]$ or $[\$]^{2} \cdot\left(1-\sqrt[\mathrm{c}]{1-\mathrm{t}^{\mathrm{C}}}\right)+$ $\alpha_{1}$. (Ideal Risk Min $)[\$]$ or $[\$]^{2} . \mathrm{t}, \quad$ Where $\quad \psi_{O C_{P R P S D}}=$ Constant, $\psi_{O C_{P R P S D}}>$ 0 and Due to (FIR[\%])

$\left(M-R C_{P_{A S}>U_{I n v}}\right)[\$]\{t\}=\psi_{\left(M-R C_{P_{A S}>U_{I n v}}\right)} \times$

$\frac{1}{\left(\text { Ideal Risk }_{\text {Min }}\right)[\$] \text { or }[\$]^{2} \cdot\left(1-\sqrt[C]{1-\mathrm{t}^{\mathrm{C}}}\right)+\alpha_{1} \cdot\left(\text { Ideal Risk }_{\operatorname{Min}}\right)[\$] \text { or }[\$]^{2} . \mathrm{t},}$, Where $\psi_{\left(M-R C_{P} A S>U_{I n v}\right)}=$

Constant , $\psi_{\left(M-R C_{P_{A S}>U_{\text {Inv }}}\right)}>0$, Due to $\left(F C_{\text {Increased }}[\$], V C_{\text {Increased }}[\$]\right)$

$\left.\left(M-R C_{P_{A S-B D L}>U_{I n v}}\right)[\$]\{t\}=\psi_{\left(M-R C_{P} A S-B D L\right.}>U_{I n v}\right) \times$

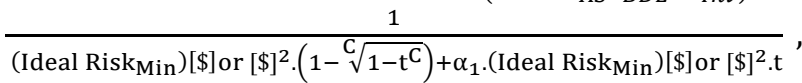

Where $\psi_{\left(M-R C_{P_{A S}-B D L}>U_{I n v}\right)}=$ Constant, $\psi_{\left(M-R C_{P_{A S}-B D L}>U_{I n v}\right)}>$

0, Due to $\left(D F_{R C T}[\%], V C_{\text {Increased }}[\$]\right)$ 
$\left(M_{R C B>A C E}\right)[\$]\{t\}=\psi_{\left(\left(M_{R C B>A C E}\right)\right)} \times$
$\frac{1}{\left.\text { Ideal Risk }_{\text {Min }}\right)[\$] \text { or }[\$]^{2} \cdot\left(1-\sqrt[C]{1-\mathrm{t}^{\mathrm{C}}}\right)+\alpha_{1} \cdot\left(\text { Ideal Risk }_{\text {Min }}\right)[\$] \text { or }[\$]^{2} \cdot \mathrm{t}}$, Where $\psi_{\left(\left(M_{R C B>A C E}\right)\right)}=$
Constant, $\psi_{\left(\left(M_{R C B>A C E}\right)\right)}>0$, Due to $\left(D F_{R C T}[\%]\right)$

As already stated, these variables take into their scope all the constraints that have been imposed by the described problem statement. All other equations are formulated in terms of the variable representing the $\mathrm{x}$-axis in the operating curves model. The operating curves model with the identified set of equations clearly is a targeted positioning of the fundamental trade-off variable, and is a mathematical correlation between the dependent and the independent variable. Hence the mathematical operating curves model takes into its scope conceptual working capital management and the ETO production approach and clearly satisfies the purpose and rules stipulated by the parent logistic operating curves theory (see Fig. 3).

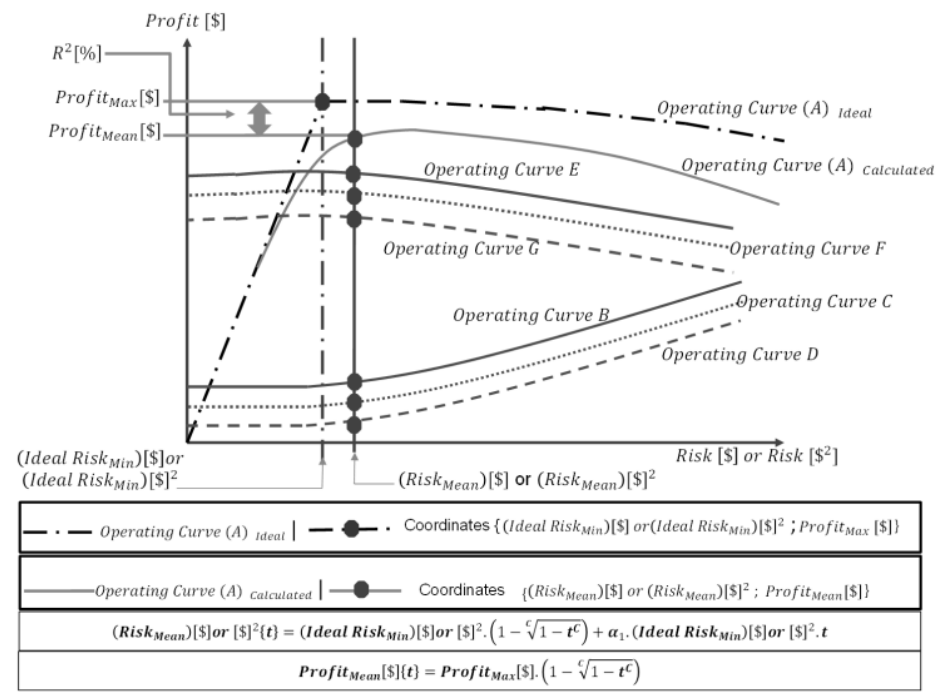

Fig. 3. Calculated Operating Curves Model

Operating Curve $(A)_{\text {Ideal }}$ :

Profit $_{\text {Max }}[\$]$ vs. $\left(\right.$ Ideal Risk $\left._{\text {Min }}\right)[\$] \operatorname{or}\left(\right.$ Ideal Risk $\left._{\text {Min }}\right)[\$]^{2}$

Operating Curve $(A)$ Calculated:

Profit $_{\text {Mean }}[\$]$ vs. $\left(\operatorname{Risk}_{\text {Mean }}\right)[\$]$ or $\left(\operatorname{Risk}_{\text {Mean }}\right)[\$]^{2}$

Operating Curve B : $(A C)[\$]$ vs. $\left(\right.$ Risk $\left._{\text {Mean }}\right)[\$]$ or $\left(\right.$ Risk $\left._{\text {Mean }}\right)[\$]^{2}$

Operating Curve C: $\left(O C_{E M S D}\right)[\$] v s .\left(\right.$ Risk $\left._{\text {Mean }}\right)[\$]$ or $\left(\right.$ Risk $\left._{\text {Mean }}\right)[\$]^{2}$

Operating Curve D: $\left(O C_{P R P S D}\right)[\$] v s .\left(\operatorname{Risk}_{\text {Mean }}\right)[\$]$ or $\left(\operatorname{Risk}_{\text {Mean }}\right)[\$]^{2}$

Operating Curve E:

$\left(M-R C_{P_{A S}>U_{I n v}}\right)[\$] v s\left(\operatorname{Risk}_{M e a n}\right)[\$]$ or $\left(\operatorname{Risk}_{\text {Mean }}\right)[\$]^{2}$ 
Operating Curve F:

$\left(M-R C_{P_{A S-B D L}>U_{\text {Inv }}}\right)[\$] v s$. $\left(\right.$ Risk $\left._{\text {Mean }}\right)[\$]$ or $\left(\operatorname{Risk}_{\text {Mean }}\right)[\$]^{2}$

Operating Curve G: $\left(M_{R C B>A C E}\right)[\$] v s .\left(\right.$ Risk $\left._{\text {Mean }}\right)[\$]$ or $\left(\right.$ Risk $\left._{\text {Mean }}\right)[\$]^{2}$

\section{Conclusion}

A mathematical operating curves model, that correlates the important operations of the engineer-to-order manufacturer with the important postulates of conceptual workingcapital management, has been formulated. In doing so, the model has completely complied with the rationale in the goal of the parent logistic operating curves model. Which is target positioning of the significant and important set of trade-off variables.

Orientation to the engineer-to-order production approach, has served as a constraint both qualitatively and quantitatively. As target positioning requires being most specific, a micro-level consideration for the important operations of the engineer-to-order production approach has been done. This consideration enabled recognition of potential variables of interests that satisfy the requirements as well as conceptually correlate with the postulates of working-capital management. It is a sincere belief that the output of the research potentially could be another small expansion, amongst many major expansions to the parent logistic operating curves theory.

\section{References}

1. Richard A. Brealey, Stewart C. Myers, Alan J. Marcus (2001) Fundamentals of Corporate Finance: Selected Material. With Additional Material From, Fundamentals of Corporate Finance, Alternate Fifth Edition; Essentials of Corporate Finance, Second Edition, 3rd edn. The McGraw-Hill Companies, Inc.

2. Lorenzo A. Preve, Virginia Sarria-Allende (2010) Working Capital Management. Financial Management Association Survey and Synthesis Series. Oxford University Press

3. Douglas H. Grabenstetter, John M. Usher (2014) Developing due dates in an engineer-to-order engineering environment. International Journal of Production Research 52: 6349

4. Schuh G, Schmidt C, Helmig J (2012) Prozesse. In: Schuh G, Stich V (eds) Grundlagen der PPS, 4.th edn. Springer Vieweg, Berlin, pp 109-194

5. Jonathan Gosling, Mohamed M. Naim (2009) Engineer-to-Order Supply Chain Management : A literature review and research agenda. International Journal of Production Economics 122 (2009): 741

6. Earl C, Song DP, Hicks C (2003) Planning Complex Engineer-to-Order Products. Recent Advances in Integerated Design and Manufacturing in Mechanical Engineering: 463-472

7. Peter Nyhuis, Hans-Peter Wiendahl (2009) Fundamentals of Production Logistics: Theory, Tools and Applications, 2nd edn. Springer-Verlag Berlin Heidelberg, Berlin 